\title{
COMPREHENSIVE ASSESSMENT OF CAPSTONE SENIOR DESIGN COURSE COMPRISED OF STUDENTS FROM DIFFERENT ENGINEERING PROGRAM MAJORS
}

\author{
Prathivadi Ravikumar, Blair McDonald, William Pratt, Il-Seop Shin, and Khaled Zbeeb \\ Western Illinois University - Quad Cities, Moline, IL 61265, USA \\ p_b_ravikumar@yahoo.com, b-mcdonald2@wiu.edu,wf-pratt@wiu.edu, i-shin@wiu.edu, k-zbeeb@wiu.edu
}

\begin{abstract}
The Accreditation Board for Engineering and Technology (ABET) is the premier organization that accredits many engineering programs in the US. Assessment by ABET that Student Outcomes are achieved is a central part of its decision to accredit any program. The programs in engineering at Western Illinois University (WIU) place significant emphasis in the Capstone Senior Design course as part of the overall plans to seek accreditation. For example, it is the only course wherein all eleven student outcomes identified by ABET are formally assessed, thereby making it a comprehensive assessment. But assessment is challenging because there are many more variables than normal in a Capstone Senior Design course compared to traditional courses. This paper discusses the framework of assessment plans, schedules, rubrics, implementation, data collection, analysis, and continuous improvements in detail under this challenging environment in the Senior Design course at WIU.
\end{abstract}

Keywords: Assessment, Engineering, ABET, Capstone Senior Design, Different Majors

\section{INTRODUCTION}

The Accreditation Board for Engineering and Technology (ABET) [1] is the premier organization that accredits many engineering programs in the US. Assessment by ABET that Student Outcomes are achieved is a central part of its decision to accredit any program. At our university, the programs in engineering place significant emphasis in the Capstone Senior Design course as part of the overall plans to seek accreditation. For example, it is the only course where all eleven student outcomes identified by ABET are formally assessed, thereby making it a comprehensive assessment. This is a sound choice because of the nature of the course in that it gives the students a capstone experience through industry sponsored projects. But such a sound choice also brings challenges in planning for assessment, implementing the plans, gathering assessment data from diverse constituents of the course such as the students, faculty, outside mentors, and industry sponsors. This is because there are many more variables than normal in a Capstone Senior Design course compared to traditional courses. For example, the nature of industry projects for each team could be quite different even if every student in the class is in the same major program. Just the variety of involved constituents mentioned above is another variable not found in traditional courses. Assessment challenges are compounded further when the class is made of students from different program majors and the number of students in each project team allowed to vary significantly as is the case at WIU. As much as assessment challenges are compounded due to these additional flexibilities in the programs, the flexibilities have been found to benefit the students greatly. The two majors currently offered in the School of Engineering at WIU are mechanical engineering and (general) engineering. The mechanical engineering program is currently going through its first accreditation process and the engineering program its second. A transparent, well-understood process of data collection and course assessment and evaluation is crucial for the success of such new programs. Also, early improvement and goaloriented changes will keep the programs viable in the long term [2]. The progression towards assessment at WIU has been under this backdrop. This paper discusses the framework of assessment plans, schedules, rubrics, implementation, data collection, analysis, and continuous improvements in detail under this challenging environment in the Senior Design course at WIU.

\section{ASSESSMENT PLANS AND SCHEDULE}

ABET assessment framework is established through clear definitions of related assessment aspects using terminology (for example, Student Outcomes). As much as ABET recognizes and supports the prerogative of institutions to adopt and use terminology of their choice, using ABET's terms and their implications as defined help contribute towards a more robust assessment. 
At the time of ABET's visit to campus, besides providing several expected documents for their review, a large "Continuous Improvement" poster was presented to provide a top down view of the assessment plans, implementation, results, and impact undertaken over the 2011-12 to 2016-17academic years. The poster was helpful for the instructors in that it effectively summarized the major steps undertaken and how they related to each other as a summary flowchart for the 2011-12 to 20162017 cycle. It also served as a template and promoter for detailed planning and follow-up for the next six-year cycle. The main elements of the flowchart are shown in Fig. 1.

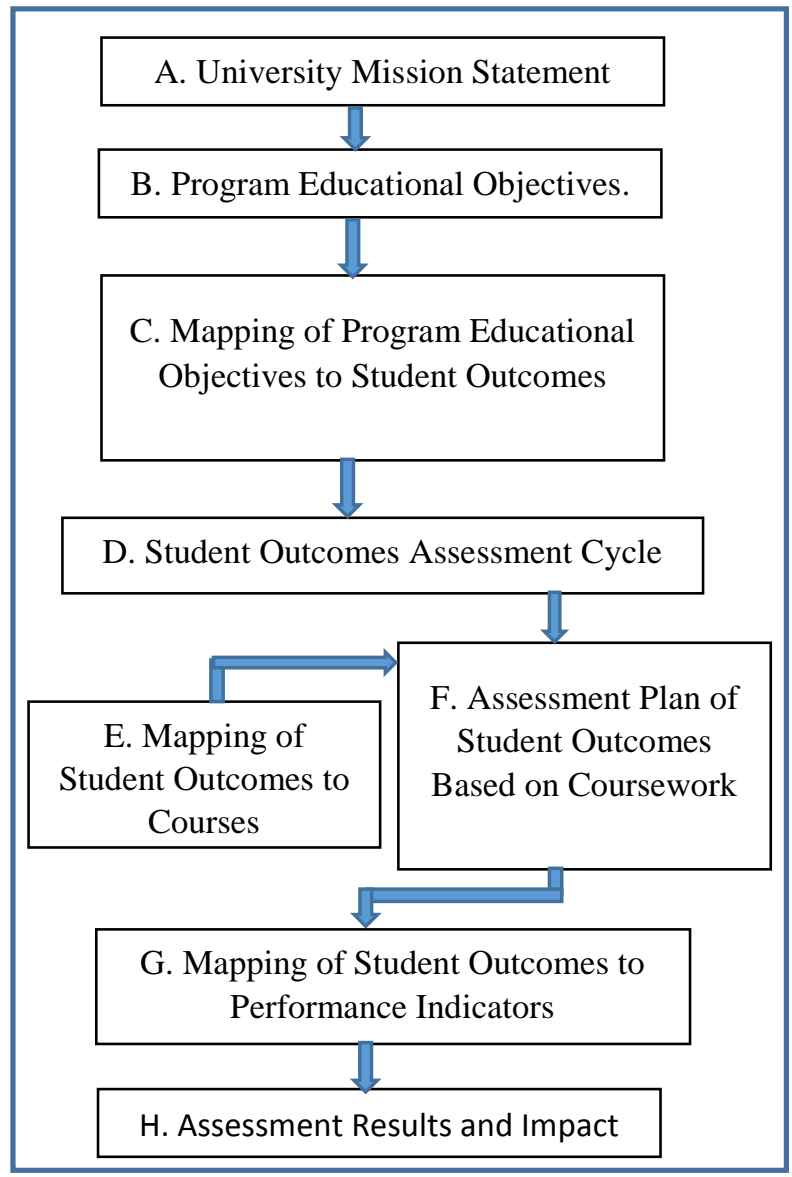

Fig.1 Six-Year Assessment Summary Flowchart

As can be seen in Fig.1, the main elements are labeled A, $\mathrm{B}, \mathrm{C}$ etc. for easy reference in this document. In this section, assessment plans (A, B, C, E, F, \& G) and schedule (D) are discussed. The Program Educational Objectives (or PEOs), (B), must be driven by the Mission of the University (A). PEOs are career and professional accomplishments within 3-5 years following graduation. The Mission of WIU is: "WIU empowers students, faculty, and staff to lead dynamic and diverse communities. We provide student-centered undergraduate and graduate programs characterized by innovative teaching, research, and service, grounded in interdisciplinary, regional and global perspectives. We engage our students in educational opportunities guided by a professional and diverse faculty and staff in collaboration with alumni and community partners". Consistent with this mission, the PEOs for both the engineering programs have been generated as follows: Create: Graduates will analyze problems and create innovative designs based on sound engineering principles and that consider functionality, cost effectiveness, sustainability, safety, aesthetics, and satisfy the requirements of a customer.

Communicate: Graduates will use modern technology and design tools, work effectively as individuals and in teams, and clearly and effectively communicate ideas in written, oral, and graphical form.

Learn: Graduates will increase their personal knowledge and skills through graduate work and other professional education, to maintain an appropriate level of expertise and remain current in their chosen profession.

Citizenship: Graduates will serve as a team member or as a team leader and use the principles of ethical leadership, both in their chosen profession and in other activities.

Community: Graduates will contribute their time and talents to improve their communities.

It should be noted that Fig.1discussions are based on the detailed ABET Self-Study report prepared for and sent to ABET by WIU for each program. For example, Mapping of PEOs to Student Outcomes (C in Fig. 1) discussed next are detailed as required under the Criterion 3 Section of the Self-Study Report. The student outcomes selected by WIU are the ones recommended by ABET:

a. an ability to apply knowledge of mathematics, science and engineering

b. an ability to design and conduct experiments, as well as to analyze and interpret data

c. an ability to design a system, component, or process to meet desired needs within realistic constraints such as economic, environmental, social, political, ethical, health and safety, manufacturability, and sustainability

d. an ability to function on multidisciplinary teams

e. an ability to identify, formulate, and solve engineering problems

f. an understanding of professional and ethical responsibility

g. an ability to communicate effectively

h. the broad education necessary to understand the impact of engineering solutions in a global, economic, environmental, and societal context

i. a recognition of the need for, and an ability to engage in life-long learning

j. a knowledge of contemporary issues

k. an ability to use the techniques, skills, and modern engineering tools necessary for engineering practice. 
The Program Educational Objectives are achieved by making use of multiple Student Outcomes. Student Outcomes are the skills and knowledge students should have upon graduation. The mapping identified by $\mathrm{C}$ in Fig.1 is shown in Table 1. The Student Outcomes are in turn each accomplished in multiple courses throughout the programs as described later.

Table 1: Mapping of Program Educational Objectives to Student Outcomes

\begin{tabular}{|c|c|c|c|c|c|}
\hline \multirow[b]{2}{*}{$\begin{array}{l}\text { Student } \\
\text { Outcomes }\end{array}$} & \multicolumn{5}{|c|}{ Program Educational Objectives } \\
\hline & 莺 & 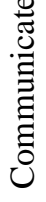 & 恕 & 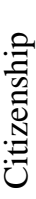 & 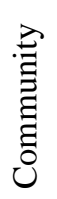 \\
\hline a & $\sqrt{ }$ & & & & \\
\hline $\mathrm{b}$ & $\sqrt{ }$ & & & & \\
\hline $\mathrm{c}$ & $\sqrt{ }$ & & & $\sqrt{ }$ & $\sqrt{ }$ \\
\hline $\mathrm{d}$ & & $\sqrt{ }$ & & & \\
\hline e & $\sqrt{ }$ & & & & \\
\hline $\mathrm{f}$ & $\sqrt{ }$ & & & $\sqrt{ }$ & $\sqrt{ }$ \\
\hline $\mathrm{g}$ & $\sqrt{ }$ & $\sqrt{ }$ & & & \\
\hline $\mathrm{h}$ & $\sqrt{ }$ & & $\sqrt{ }$ & $\sqrt{ }$ & $\sqrt{ }$ \\
\hline i & & & $\sqrt{ }$ & & \\
\hline j & $\sqrt{ }$ & & $\sqrt{ }$ & $\sqrt{ }$ & $\sqrt{ }$ \\
\hline $\mathrm{k}$ & $\sqrt{ }$ & $\sqrt{ }$ & $\sqrt{ }$ & & \\
\hline
\end{tabular}

To briefly illustrate how the mapping in Table. 1 came about, the correlation between the PEO "Create" and the Student Outcomes a-c, e-h, and j-k is discussed as an example next. Student Outcomes a-c, e-h, and j-k are skills and capabilities necessary to execute effective designs and are therefore important to the accomplishment of the PEO "Create". Upon graduation, students must not only know the basics but be able to solve problems in a context driven by constraints, personal and inter-personal skills.

Just as the major means to accomplish the PEOs are the Student Outcomes as mapped in Table.1, the Student Outcomes are in turn each accomplished mainly through multiple courses throughout the programs as shown in Table. 3 (E in Fig. 1) and Table. 4 (F in Fig. 1). Table 3 maps the "informal" assessment plan to achieve Student Outcomes through all engineering courses (names of the courses can be seen at www.wiu.edu). Table.4 maps the "formal" assessment plan to achieve Student Outcomes through "core and essential" courses as per the schedule shown in Table.2 (D in Fig. 1). The letters L, M, and H indicate the degree to which courses contribute to the Student Outcomes as Low, Moderate, and High.

As seen in Table.3 and Table.4, ENGR 490 Senior Design is a comprehensive assessment course in that all the eleven (a through k) Student Outcomes are formally assessed unlike any other course wherein only a select few of the
Student Outcomes are assessed. Senior Design is the major design experience for both engineering and mechanical engineering programs. It is a two-semester sequence with students from both majors enrolled in the same class. The general format and management aspects of the course are discussed next followed by assessment details pertaining to the course.

Table 2: Student Outcomes Assessment Cycle

\begin{tabular}{|c|c|c|c|c|c|c|}
\hline \multirow[b]{2}{*}{$\begin{array}{l}\text { Student } \\
\text { Outcomes }\end{array}$} & \multicolumn{3}{|c|}{$\begin{array}{c}\text { First 3-Year } \\
\text { Cycle }\end{array}$} & \multicolumn{3}{|c|}{$\begin{array}{c}\text { Second 3-Year } \\
\text { Cycle }\end{array}$} \\
\hline & 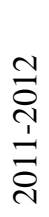 & 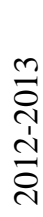 & 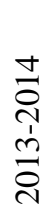 & 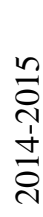 & 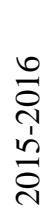 & 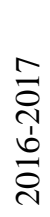 \\
\hline a & $\sqrt{ }$ & & & $\sqrt{ }$ & & \\
\hline$b$ & $\sqrt{ }$ & & & $\sqrt{ }$ & & \\
\hline $\mathrm{c}$ & & $\sqrt{ }$ & & & $\sqrt{ }$ & \\
\hline $\mathrm{d}$ & & $\sqrt{ }$ & & & $\sqrt{ }$ & \\
\hline $\mathrm{e}$ & & & $\sqrt{ }$ & & & $\sqrt{ }$ \\
\hline $\mathrm{f}$ & $\sqrt{ }$ & & & $\sqrt{ }$ & & \\
\hline $\mathrm{g}$ & $\sqrt{ }$ & & & $\sqrt{ }$ & & \\
\hline $\mathrm{h}$ & & $\sqrt{ }$ & & & $\sqrt{ }$ & \\
\hline $\mathrm{i}$ & & $\sqrt{ }$ & & & $\sqrt{ }$ & \\
\hline$j$ & & & $\sqrt{ }$ & & & $\sqrt{ }$ \\
\hline $\mathrm{k}$ & & & $\sqrt{ }$ & & & $\sqrt{ }$ \\
\hline $\begin{array}{l}\text { Program } \\
\text { Criteria (ME) }\end{array}$ & & & $\sqrt{ }$ & & & $\sqrt{ }$ \\
\hline
\end{tabular}

Table 3: Mapping of Student Outcomes to Courses

\begin{tabular}{|l|c|c|c|c|c|c|c|c|c|c|c|}
\hline & \multicolumn{10}{|c|}{ Student Outcomes } \\
\hline Course & a & b & c & d & e & f & g & h & i & j & k \\
\hline ENGR 105 & H & & M & & H & & H & & & & H \\
\hline ENGR 211 & H & & & & H & M & H & & & & H \\
\hline ENGR 212 & H & & & & H & & M & & & & H \\
\hline ENGR 220 & H & & H & & H & & & & & & \\
\hline ENGR 251 & H & H & & & H & & H & & & & H \\
\hline ENGR 271 & H & & H & & H & & & & & & H \\
\hline ENGR 300 & H & & & H & & M & & & & & H \\
\hline ENGR 310 & H & H & & & H & & H & & & & H \\
\hline ENGR 320 & H & M & H & & M & L & L & & & & M \\
\hline ENGR 322 & H & H & H & & H & & M & & & & H \\
\hline ENGR 331 & M & M & & & & H & H & & & & M \\
\hline ENGR 340 & & & M & & M & & & & & M & H \\
\hline ENGR 351 & H & H & M & H & H & & H & H & H & H & H \\
\hline ENGR 370 & H & & H & & H & & & & & & \\
\hline ENGR 410 & H & M & & & H & M & & & & & H \\
\hline ENGR 411 & H & & H & & H & & H & & & & H \\
\hline ENGR 470 & H & & H & & H & & & & & & \\
\hline ENGR 472 & H & & H & & H & & & & & & \\
\hline ENGR 473 & H & & H & & H & & & & & & \\
\hline ENGR 481 & H & H & H & & H & H & H & & & & H \\
\hline ENGR 482 & & & M & M & M & & M & & M & & M \\
\hline ENGR 490 & H & H & H & H & H & H & H & H & H & H & H \\
\hline
\end{tabular}


Table 4: Assessment Plan of Student Outcomes Based on Coursework

\begin{tabular}{|l|c|c|c|c|c|c|c|c|c|c|c|}
\hline & \multicolumn{10}{|c|}{ Student Outcomes } \\
\hline Course & a & b & c & d & e & f & g & h & i & j & k \\
\hline ENGR 300 & H & & & & & & & & & & H \\
\hline ENGR 310 & & H & H & & & & & & & & \\
\hline ENGR 320 & & & H & & H & & & & & & \\
\hline ENGR 322 & H & & & & & & & & & & H \\
\hline ENGR 331 & & & & H & & M & H & M & & & \\
\hline ENGR 340 & & & H & & & & & & M & M & \\
\hline ENGR 351 & & H & & & & & & & & & \\
\hline ENGR 370 & & & H & & H & & & & & & \\
\hline ENGR 411 & & & & & H & & & & & & H \\
\hline ENGR 490 & H & H & H & H & H & H & H & H & H & H & H \\
\hline
\end{tabular}

The courses abbreviated in Table 4 are:

ENGR 300 Engineering Thermodynamics

ENGR 310 Fluid Dynamics

ENGR 320 Mechanical Design I

ENGR 322 Mechanical Design II

ENGR 331 Engineering Project Management

ENGR 340 Manufacturing Engineering

ENGR 351 Material Science

ENGR 370 Electronics I

ENGR 411 Heat Transfer

ENGR 490 Senior Design

\section{FORMAT AND MANAGEMENT OF SENIOR DESIGN COURSE}

The ENGR 490 Senior Design Course in the School of Engineering at WIU is a two-semester long course. The focus in the first semester is on design synthesis through a rigorous design process to generate and evaluate alternative design concept solutions to problems. Problems are from industry that require students to work in teams on projects. Teams undertake major portion of the product development on a chosen final concept during the second semester. Product development could be some or all of major activities such as engineering analysis, designing for performance and robustness, designing for manufacture and assembly, designing for cost, simulation, solid modeling, drawing, building prototypes and testing. The management of the course from the instructor's perspective by semester is discussed next.

First Semester involves forming teams; assignment of projects; lectures on design process and methods; and application of the learnt process and methods to the project at hand. Teams in the Senior Design course at WIU are somewhat unique in that they can be comprised of students from both majors and can be even a single-student working with a team of industry contacts associated with the project. Teams meet with their sponsor contacts at least a few times during the course of the first semester. These include meeting the sponsor to gain a better understanding of the project early on in the semester; to discuss two to five best design concepts realized by the team sometime around the three-fourth way point of the semester so that the sponsor can select the best concept for further product development; to present the final design both in oral and written/electronic form at the end of the semester; to have additional design reviews if needed by the sponsor.

Second semester involves product development as outlined earlier. Testing of the prototype will be undertaken if it is part of the Scope of Project. If prototype development is not part of the Scope of Project and hence no testing in all likelihood, team will focus on further product development activities such as optimizing the design in greater detail and improving details to be production ready. Meetings with the sponsor during the second semester will be by arrangement and as often as necessary. A final report and presentation and delivery of prototype if applicable will occur at the end of the second semester.

\section{ASSESSMENT OF SENIOR DESIGN COURSE}

With the Senior Design course providing real-world capstone experience as outlined above, it is a focal point of assessment amongst the courses included for formal assessment. As mentioned earlier, it is the only course wherein all eleven (a through $\mathrm{k}$ ) student outcomes are assessed over each of the two 3-year cycles between accreditation reviews. At WIU, the assessment plan is to have the same Performance Indicators of each outcome across every course. The difference for the courses will be course specific rubrics for the Performance Indicators to implement assessment, collect data, evaluate, analyze, and make continuous improvement.

Student Outcome "c" is chosen as a good candidate for illustrating next the Performance Indicators, the rubrics under them as applied to Senior Design, implementation, data collection, evaluation, analysis, and continuous improvement.

Student Outcome " $\mathrm{c}$ " as defined by ABET is "an ability to design a system, component, or process to meet desired needs within realistic constraints such as economic, environmental, social, political, ethical, health and safety, manufacturability, and sustainability".. The two Performance Indicators that are used in all courses for Student Outcome "c" are:

(1) Identify constraints and requirements of the design of a system, component, or process.

(2) Design a system, component, or process that meets the design requirements and is within the constraints imposed. 
With small class sizes in new programs early on, the rubric for direct measure was the assessment by the faculty advisor of the Project Final Report submitted by every team. The evaluation was done on a Likert Scale to address each Performance Indicator and a composite score for each team was realized by giving equal weights to each performance indicator. The average of all teams' composite scores was the score for the entire class. But as the programs grew and there were about ten project teams at any particular time, it became apparent that a more specific set of rubrics, implementation, data collection, and analysis was necessary to maintain reliable assessment and continuous improvement ( $\mathrm{H}$ in Fig. 1). This led to the development of the rubrics' template shown in Table. 5 and the evaluation template, an Excel file, shown in Table. 6, both for Student Outcome "c" (G and H in Fig. 1). The templates are shown re-formatted to comply with the format requirements for this paper. Table. 6 is shown on the last page of this paper because a two-column format is not suitable. It should be noted that the rubric template shown in Table. 5 is an online "fill-in" form that will be filled out by each team using information primarily in their reports so that there is clear and easily accessible information pertinent to the assessed student outcome. Faculty advisors will be using additional data collected through other means such as survey feedback from industry contacts regarding student performance on the outcome before filling out the evaluation template.

Table 5: Rubrics for Student Outcome "c"

\begin{tabular}{|l|}
\hline Title (of the Project) \\
\hline Purpose of the Design: \\
\hline Requirements of the Design: \\
Include your Table of Objectives that was sent to the \\
sponsor; include the final Table of Objectives that was \\
sent back to you by the sponsor as the final version; \\
write a narrative explaining what these tables are and \\
how they came about; include House of Quality (HOQ); \\
Write a narrative with a focus on the customer \\
requirements (Objectives) and their translation to \\
specifications (technical or engineering or design \\
requirements) along with their target ranges. \\
\hline Applicable Standards, Constraints, or Limitations: \\
Standards: List and explain how various standards have \\
been or will be used in the project. It is especially \\
important to include standards that apply to the \\
sponsoring company's products or practices. You \\
should also include standards you have already used or \\
will be using when applicable, for example, ANSI B4.2 \\
for fits and tolerances. Write a brief narrative of how \\
other constraints or limitations were translated to \\
meaningful requirements for the design. \\
\hline Design Approach: Include the Symmetrical Problem \\
Solution Model [3] and the Mechanical Design Process \\
Model.[4]
\end{tabular}

Write a narrative of what and how the design process (focus on the Symmetrical Problem Solution Model) was utilized in your project (Method of Investigation section of your first semester report will help). Include in the narrative your emphasis on obtaining and using the customer's requirements and technical constraints in design methods such as the Objectives Tree, Table of Objectives, House of Quality, Advanced Decision Matrix, and Performance Evaluation. Also emphasize the use of creative methods such as FAF and 6-3-5 to realize many alternative design solution possibilities.

Analysis and Performance:

Include analysis and results as brief summaries. Write how through analysis and iteration, performance was achieved by meeting target ranges.

Conclusions:

Make projections relative to economic, environmental, health, safety or social impact of your design solution.

Continuous Improvement:

Identify lessons learned for future developments.

\section{CONCLUSIONS}

This paper discussed the framework of assessment plans, schedules, rubrics, implementation, data collection, analysis, and continuous improvements in detail in the Senior Design course at WIU under flexible and challenging situations. The paper has demonstrated that with a clear understanding of the Mission of the University, the educational objectives expected by ABET, and comprehensive assessment backed by effective documentation can lead to quality education for students through continuous improvement.

\section{REFERENCES}

[1] ABET (Accreditation Board for Engineering and Technology). Available as of 2/17/2018 from http://www.abet.org

[2] Monika Bubacz, Robert Rabb, Jason Howison, Kevin Skenes, Patrick Bass, Jason Geathers, and Emily Book, "ABET program assessment (A.P.A) for a new engineering program," in Proc. 2017 ASEE Zone 2 Conf., (San Juan, Puerto Rico, March 2-5, 2017), 11 pp., 2017. Available as of 2/17/2018 from

http://zone2.asee.org/sessions/program/3/29.pdf

[3] Nigel Cross, Engineering Design Methods: Strategies for Product Design.. New York, NY: John Wiley \& Sons, 1994 $\left(2^{\text {nd }} e d.\right), 179$ pp. \{ISBN: 0-471-94228-6\}

[4] David G. Ullman, The Mechanical Design Process. New York, NY: McGraw-Hill, 2003 ( $3^{\text {rd }}$ ed.), 415 pp. \{ISBN: 007-237338-5\} 
Table 6: Template for Evaluating Student Outcome "c" Evaluator:

COURSE: SEMESTER:

YEAR: MAJOR:

\section{Data Sources}

Team Final Report in Project Binder, ABET "a through k" Team Summary in the last Appendix of Final Report, and Completed Template 3c Template by Team
TEAM \#:
PROJECT:

3c: Learning Outcome: an ability to design a system, component, or process to meet desired needs within realistic constraints such as economic, environmental, social, political, ethical, health and safety, Reference: Design (Word)

(1) Identify constraints and requirements of the design of a system, component, or process.

\begin{tabular}{|c|c|c|c|c|c|c|c|}
\hline a) Purpose of the Design & $5 \%$ & \multicolumn{3}{|c|}{$\begin{array}{l}\text { States purpose correctly but missing some } \\
\text { elements such as motivation, the role of } \\
\text { the design, or it's importance. }\end{array}$} & \multicolumn{3}{|c|}{$\begin{array}{l}\text { Clearly states the purpose of the design, } \\
\text { what it is to accomplish and it's } \\
\text { importance in the larger picture or } \\
\text { assembly. }\end{array}$} \\
\hline b) Requirements of the Design & $15 \%$ & \multicolumn{3}{|c|}{$\begin{array}{l}\text { Extracts the voice of the customer, } \\
\text { determines the most obvious } \\
\text { requirements of the design but has trouble } \\
\text { translating them to design specifications } \\
\text { with performance goals. }\end{array}$} & \multicolumn{3}{|c|}{$\begin{array}{l}\text { Expertly extracts the voice of the customer, } \\
\text { determines the requirements of the design } \\
\text { in detail, and translates these to design } \\
\text { specifications with performance goals. }\end{array}$} \\
\hline c) Standards, Constraints, Limitations & $10 \%$ & \multicolumn{3}{|c|}{$\begin{array}{l}\text { Identifies most or obvious standards, } \\
\text { constraints, or limitations and but has } \\
\text { trouble translating those to meaningful } \\
\text { requirements of the design }\end{array}$} & \multicolumn{3}{|c|}{$\begin{array}{l}\text { ldentifies all appropriate standards to be } \\
\text { used, logical constraints, and limitations } \\
\text { and translates those to meaningful } \\
\text { requirements of the design. }\end{array}$} \\
\hline d) Design Approach & $20 \%$ & \multicolumn{3}{|c|}{$\begin{array}{l}\text { Correctly identifies the most obvious } \\
\text { design, but is missing or has difficulty } \\
\text { selecting alternative feasible designs, } \\
\text { and/or analyzing the strengths and } \\
\text { weaknesses of each design. }\end{array}$} & \multicolumn{3}{|c|}{$\begin{array}{l}\text { Uses the voice of the customer, house of } \\
\text { quality results, and appropriate standards } \\
\text { to determine feasible designs, and } \\
\text { expertly analyzes the strengths and } \\
\text { weaknesses of each design. }\end{array}$} \\
\hline $\begin{array}{l}\text { (2) Design a system, component, or process } \\
\text { that meets the design requirements and is } \\
\text { within the constraints imposed. }\end{array}$ & Weight & \multicolumn{3}{|c|}{ Level 3} & \multicolumn{3}{|c|}{ Level 5} \\
\hline a) Design of component or system & $30 \%$ & \multicolumn{3}{|c|}{$\begin{array}{l}\text { Design satisfies the critical requirements } \\
\text { but is not optimal, or efficient, or does not } \\
\text { adequately satisfy all the customer's } \\
\text { requirements. Either function or } \\
\text { performance of the design is not verified } \\
\text { adequately. }\end{array}$} & \multicolumn{3}{|c|}{$\begin{array}{l}\text { Design shows mastery of methods, } \\
\text { standards, constraints and voice of the } \\
\text { customer. Design efficiently satisfies all } \\
\text { requirements. Verifies function and } \\
\text { performance of the design }\end{array}$} \\
\hline b) Conclusions & $20 \%$ & \multicolumn{3}{|c|}{$\begin{array}{l}\text { Correctly determines obvious conclusions } \\
\text { but has trouble extrapolating those results } \\
\text { to useful subsequent actions. }\end{array}$} & \multicolumn{3}{|c|}{$\begin{array}{l}\text { Summarizes major points of the design and } \\
\text { process, makes projections relative to } \\
\text { economic, environmental, health, safety or } \\
\text { societal impact. Gives expert advice on } \\
\text { lessons learned for future developments. }\end{array}$} \\
\hline \multirow[t]{10}{*}{ Project } & $3 c(1) a)$ & $3 c(1) b)$ & $3 c(1) c)$ & $3 c(1) d)$ & $3 c(2) a)$ & $3 c(2) b)$ & Overall Eval \\
\hline & & & & & & & 0.0 \\
\hline & & & & & & & 0.0 \\
\hline & & & & & & & 0.0 \\
\hline & & & & & & & 0.0 \\
\hline & & & & & & & 0.0 \\
\hline & & & & & & & 0.0 \\
\hline & & & & & & & 0.0 \\
\hline & & & & & & & 0.0 \\
\hline & & & & & & & 0.0 \\
\hline \multicolumn{4}{|c|}{ Compiled score for all projects $\gg 3 c(1), 3 c(2), 3 c$ Overall } & & & & \\
\hline
\end{tabular}

CEEA18; Paper 162

University of British Columbia; June 3-6, 2018
-6 of $6-$ 